\title{
INTIMATE PARTNER VIOLENCE AND CONTRA CEPTIVE USE AMONG MARRIED WOMEN IN SOUTH-SOUTH NIGERIA
}

\author{
Olowoporoku Ayodeji John \\ Department of Demography and Social Statistics, Obafemi Awolowo University, Ile-Ife, Nigeria. \\ Ajayi Adeola \\ Department of Public Administration, Obafemi Awolowo University, Ile-lfe, Nigeria.
}

\begin{abstract}
This study outlines intimate partner violence and contraceptive use among married women in South-South Nigeria. Attempt was made to investigate association between intimate partner violence and use of contraception among married women in south-south Nigeria. This study utilized secondary data. Secondary data were extracted from 2013, Nigeria Demographic and Health Survey (NDHS) dataset. Out of the 38,948 women interviewed, this study employed sample of the 4,932 women representing the number of married women in South-South Nigeria. The analysis were done in two stages of univariate and bivariate analysis. The result showed that almost all the married women use contraceptive which indicated that contraceptive use varies significantly by age of married women, education, place of resident, wealth status and occupation. The study concluded that married women who have ever experienced sexual violence are more likely to adopt contraception than married women whose experienced physical violence and emotional violence.
\end{abstract}

\section{Introduction}

Intimate partner violence as a confrontation between family or household members that typically involve physical abuse, sexual abuse or fear of physical harm (Ndhs, 2013). The World Health Organization (2006) defines intimate partner violence as "the intentional use of physical force or power, threatened or actual, against oneself, another person, or against a group or community that either results in or has a high likelihood of resulting in injury, death, psychological harm, or deprivation". Studies showed that women in urban center report experience intimate partner violence than counterpart in rural area. Intimate partner violence has become global concern and affects millions of women each year and has been recognized as a leading cause for poor health, disability, and death among women of reproductive age.

Specifically, within the Nigeria intimate partner violence cut across all socioeconomic and cultural background, 19\% of women in South-South have been victims of Intimate Partner Violence (Ndhs, 2013). Many countries in the world now formulate policy to reduce intimate partner violence to barely minimum if not totally eradicated. Sources note that there is no national law on intimate partner violence in Nigeria. Sources reported that the violence against persons (prohibition) (VAPP) bill was passed in the House of Representatives in 2013 but remains before the Senate awaiting approval. The bill which covers domestic and gender-based violence also include more comprehensive definition of rape, harsher sentences for rape and other sexual offences, compensation for rape victims, institution protection for further abuse through restraining order and a new fund to support the rehabilitation of victims of violence. State government within the Nigeria are not left behind in formulate policy to tackle intimate partner violence against women. 


\section{Data and Methods}

This study used data from the Nigeria Demography and Health Survey (NDHS) data set of 2013. NDHS is the nationally representative stratified, self-weighting probability sample of women age 15-49 years. Sample design in the collection of NDHS data involved multi stage sampling techniques. The procedure involved the division of the country into state. Each state was sub-divided into local government areas (LGAs) and each LGA was divided into localities and each locality was further sub-divided into different census enumeration area (EAs). Each EA was classified as urban and rural based on a defining criterion, where individual household were randomly sampled and successfully interviewed (NPC and ORC Marcro 2013). Out of total numbers of 38,948 omen of reproductive age 15-49 interviewed in NDHS, 2013. The study makes use of information on the 4,932 women representing the number of married women in SouthSouth Nigeria.

\section{Data analysis}

Stata version 12 would be used for data analysis. The analysis would be in two stages. The first is the univariate analysis in which distribution of respondents will be presented according to background variable. The second stage is the bivariate analysis in which two variables are considered at a time. The relationship between variable are established and the statistical significance of such variable is tested. The chi-square test would be used in this stage. Frequency will be run for all the variables to know the frequency and percentage distribution of each of the variables. Chi-square test is applied where the variable are categorical. The variable to be used are categorical in nature such as age, education, place of resident, wealth index and so on.

\section{Data analysis plan}

Univariate analysis involved Percentage distribution of respondents' socio-demography factors, Percentage distribution of intimate partner violence and Percentage distribution of contraceptive use.

Bivariate analysis involved, Cross tabulation of socio-demography factors against intimate partner violence in South-South Nigeria, Cross tabulation of socio-demography factors against contraceptive use and cross tabulation of intimate partner violence against contraceptive use.

\section{Results}

This section presents the analysis of socio-demography characteristic of respondent and other variables that are important to the study. In particular socio-demography characteristics of married women in SouthSouth Nigeria and these might influence contraceptive use. Information on a total number of 4,942 married women in South-South was analyzed.

\section{Distribution of respondents by socio-demographic characteristics}

The distribution of respondent's socio-demographic characteristics as presented in table below shown that majority of the respondents (20.90\%) are in age group 15-19 years which implied that married women tend to be younger, $(18.21 \%)$ are within the age $25-29,(17.56 \%)$ are within the age20-24, (13.78\%) are within the age $30-34,(12.41 \%)$ are within the age $35-39,(8.81 \%)$ are within the age $40-44$ while $(8.32 \%)$ are within age $45-49$.More than half $(57.56 \%)$ of respondents had secondary education, $23.15 \%$ had primary education, $(14.24 \%)$ had tertiary education while $(5.05 \%)$ had no education. With regard to occupation majority $(33.23 \%)$ of the respondents were not working while $(7.69 \%)$ engaged in professional, $(1.38 \%)$ were into clerical, $(28.23 \%)$ were into sales, $(2.15 \%)$ were into agriculture self- employ, $(13.40 \%)$ were employed into agriculture, $(8.01 \%)$ were into services, $(5.24 \%)$ were into skilled manual and $(0.01 \%)$ were into unskilled manual. In term of place of residence, more than half $(61.30 \%)$ of respondents lives in rural area while $(38.70 \%)$ lives in urban center. Wealth status measure by wealth index, majority $(34.81 \%)$ of respondents were within richest index, $(32.08 \%)$ were within richer index, $24.20 \%$ were within middle index, $8.47 \%$ were within poorer index while $0.43 \%$ were within poorest index.
Age
Region (South -South)
Percentage
$15-19$
1032.99
$20.90 \%$ 


\begin{tabular}{|c|c|c|}
\hline $20-24$ & 867.95 & $17.56 \%$ \\
\hline $25-29$ & 900.06 & $18.21 \%$ \\
\hline $30-34$ & 681.30 & $13.78 \%$ \\
\hline $35-39$ & 613.33 & $12.41 \%$ \\
\hline $40-44$ & 435.34 & $8.81 \%$ \\
\hline $45-49$ & 411.37 & $8.32 \%$ \\
\hline Total & 4942.33 & $100 \%$ \\
\hline Education & Region (South- South) & Percentage \\
\hline No education & 249.42 & $5.05 \%$ \\
\hline Primary & 1144.38 & $23.15 \%$ \\
\hline Secondary & 2844.63 & $57.56 \%$ \\
\hline Higher & 703.90 & $14.24 \%$ \\
\hline$\underline{\text { Total }}$ & 4942.33 & $100 \%$ \\
\hline Occupation & Region (South-South) & Percentage \\
\hline Not working & 1633.97 & $33.23 \%$ \\
\hline Professional/Technical & 377.96 & $7.69 \%$ \\
\hline Clerical & 67.68 & $1.38 \%$ \\
\hline Sales & 1388.43 & $28.23 \%$ \\
\hline Agricultural self-employ & 105.92 & $2.15 \%$ \\
\hline Agricultural employ & 658.80 & $13.40 \%$ \\
\hline Services & 393.80 & $8.01 \%$ \\
\hline Skilled manual & 257.90 & $5.24 \%$ \\
\hline Unskilled manual & 0.54 & $0.01 \%$ \\
\hline Others & 0.95 & $0.02 \%$ \\
\hline Total & 4917.49 & $100 \%$ \\
\hline Place of resident & Region (South-South) & Percentage \\
\hline Urban & 1912.89 & $38.70 \%$ \\
\hline Rural & 3029.44 & $61.30 \%$ \\
\hline
\end{tabular}


Wealth status

Poorest

Poorer

Middle

Richer

Richest

Total
Region (South-South)

21.37

418.84

1196.12

1585.49

1720.51

4942.33
Percentage

$0.43 \%$

$8.47 \%$

$24.20 \%$

$32.08 \%$

$34.81 \%$

$100 \%$

Table1 Sources Author's work 2016(Data from the 2013 NDHS)

\section{Distribution of respondents by intimate partner violence}

The table below presented the distribution of married women in South-South Nigeria, majority (84.76\%) of respondents reported that they did not experience any physical violence while (15.24\%) experienced any physical violence. More than half $(74.86 \%)$ of respondent reported that they did not experience any emotional violence while $25.1 \%$ experienced any emotional violence. Almost (94.15\%) reported that they did not experience any sexual violence while (5.85\%) experienced any sexual violence.

\begin{tabular}{ccc} 
Experienced any physical violence & Region (South-South) & Percentage \\
No & $2,083.79$ & $84.76 \%$ \\
Yes & 374.55 & $15.24 \%$ \\
Total & $2,458.34$ & $100 \%$ \\
\hline
\end{tabular}

Experienced any emotional violence

No

Yes

Total

Experience any sexual violence

\begin{tabular}{ccc} 
No & $2,308.95 \%$ & $94.15 \%$ \\
Yes & $143.52 \%$ & $5.85 \%$ \\
Total & $2,452.47$ & $100 \%$ \\
\hline
\end{tabular}

Region (South-South) Percentage

$1,839.20 \quad 74.86 \%$

$617.68 \% \quad 25.14 \%$

$2,456.89$

$100 \%$

Region (South-South) Percentage

Table2 Sources Author's work 2016(Data from the 2013 NDHS) 


\section{Distribution of respondents by contraceptive use}

The table below shown distribution of married women in South-South Nigeria contraceptive use by method, majority $(80.81 \%)$ of respondents reported that they use contraceptive methods such folkloric, traditional and modern method while (19.19\%) use no method

\begin{tabular}{lcc} 
Contraceptive use by method & Region (South-South) & Percentage \\
No method & 948.65 & $19.19 \%$ \\
Use method & $3,993.684$ & $80.81 \%$ \\
Total & $4,942.33$ & $100 \%$ \\
\hline
\end{tabular}

Table3 Sources Author's work 2016(Data from the 2013 NDHS)

\section{Bivariate analysis}

This section presents the result of bivariate relationship between respondent socio-demographic characteristics, intimate partner violence and outcome variable (contraceptive use). The relationship between socio-demographic characteristics, intimate partner violence and contraceptive use among married women in South-South Nigeria. The analysis was done using cross tabulation as well as chi-square. Chisquare was used to test significant between contraceptive use, intimate partner violence and sociodemographic characteristics. A p-value of less than or equal to 0.05 indicate that the independent variable is significant related to the outcome.

\section{Relationship between contraceptive use and socio-demographic characteristic of married women in South-South Nigeria}

The relationship between contraceptive use and age of married women in South- South Nigeria was presented in the table below. The result showed that there is relationship between contraceptive use and age of married women in South-South Nigeria $(\mathrm{p}<0.05)$. 89\% of married women within the age 15-19 use contraceptive while $11 \%$ did not use contraceptive, $72 \%$ within the age 20-24 years use contraceptive while $28 \%$ did not use, $76 \%$ within age $25-29$ use contraceptive while $24 \%$ did not use, $79 \%$ within age 30-34 years use contraceptive while $21 \%$ did not use, $84 \%$ within the age 35-39 years use contraceptive while $16 \%$ did not use, $82 \%$ within age $40-44$ years use contraceptive while $18 \%$ did not use and $88 \%$ with the age $45-49$ use contraceptive while $12 \%$ did not use.

Following relationship between contra ceptive use and education. Finding from the study shown that there is relationship between contraceptive use and education of married women in South-South Nigeria $p<0.05$. $95 \%$ of married women in South-South Nigeria whose use contraceptive had no education while $0.5 \%$ with no education did not use contraceptive, $85 \%$ with primary education use contraceptive while $15 \%$ with primary education did not use, $80 \%$ with secondary education use contraceptive while $20 \%$ with secondary education did not use contraceptive and $72 \%$ with higher education use contraceptive while $18 \%$ with higher education did not use contraceptive.

Religion is also important indicator that was examined with contraceptive use. The result showed that there is no relationship between contraceptive use and religion practiced by married women in South-South Nigeria $\mathrm{p}>0.05(\mathrm{p}=0.3676) .79 \%$ of married women in South-South Nigeria attended catholic church use contraceptive while $21 \%$ who attended catholic church did not use contraceptive, $81 \%$ who attended other churches use contraceptive while $19 \%$ who attended other churches did not use contraceptive, $80 \%$ who practiced Islam use contraceptive while $20 \%$ who practiced Islam did not use contraceptive and $94 \%$ who practiced traditional religion use contraceptive while $0.6 \%$ who practiced traditional religion did not use contraceptive. 
Occupation was examined with contraceptive use. Finding showed that there is relationship between contraceptive use and occupation of married women in South-South Nigeria $p>0.05(\mathrm{p}=0.006) .82 \%$ of married women in South-South Nigeria whose use contraceptive were not working while $18 \%$ did not use contraceptive and were not working. $80 \%$ whose were professional use contraceptive while $20 \%$ whose were professional did not use. $69 \%$ clerical workers use contraceptive while $31 \%$ clerical workers did not use contraceptive. $80 \%$ whose were into sales business make use of contraceptive while $20 \%$ whose were into sale did not make use of contraceptive. $81 \%$ engaged in agricultural - self-employed use of contraceptive while $19 \%$ engaged in agricultural - self-employed did not use of contraceptive. 96\%agricultural employee use contraceptive while $14 \%$ agricultural - employee did not use contraceptive. $92 \%$ household and domestic use contraceptive while $0.8 \%$ household and domestic did not use contraceptive. $73 \%$ whose were into services use contraceptive while $27 \%$ whose were into services did not use contraceptive. $75 \%$ skilled manual workers use contraceptive while $25 \%$ skilled manual workers did not use contraceptive. $100 \%$ unskilled manual workers use contraceptive and $50 \%$ of people engaged in other occupation use contraceptive while $50 \%$ of people engaged in other occupation did not use contraceptive.

Following the relationship between contraceptive use and place of residence. The result showed that there is relationship between contraceptive use and place of residence of married women in South-South Nigeria $\mathrm{p}<0.05(\mathrm{p}=0.0166) .87 \%$ of married women in South-south Nigeria lives in urban center use contraceptive while $23 \%$ lives in urban did not use contraceptive. $82 \%$ lives in rural area use contraceptive use while $18 \%$ live in rural area did not use contraceptive.

Examine contraceptive use and wealth index. The finding showed that there is relationship between contraceptive use and wealth index of married women in South-South Nigeria $\mathrm{p}<0.05 .84 \%$ poorest married women in South-South Nigeria use contraceptive while 16\% poorest did not use contraceptive. $85 \%$ Poorer use contraceptive while 15\% Poorer did not use contraceptive. $86 \%$ with in Middle index use contraceptive while $14 \%$ within Middle index did not use contraceptive.79\% within Richer index use contraceptive while $21 \%$ within richer index did not use contraceptive and $77 \%$ within richest index use contraceptive while $23 \%$ within richest index did not use contraceptive.

Contraceptive

Age

$\begin{array}{lrrrrrrr} & 15-19 & 20-24 & 25-29 & 30-34 & 35-39 & 40-44 & 45-49 \\ \text { Not use } & 11 \% & 28 \% & 24 \% & 21 \% & 16 \% & 18 \% & 12 \% \\ \text { Use } & 89 \% & 72 \% & 76 \% & 79 \% & 84 \% & 82 \% & 88 \% \\ & & & & & & & \\ & & & & & \end{array}$

Contraceptive

Education

$\begin{array}{lcccc} & \text { No education } & \text { Primary } & \text { Secondary } & \text { Higher } \\ \text { Not use } & 05 \% & 15 \% & 20 \% & 28 \% \\ \text { Use } & 95 \% & 85 \% & 80 \% & 72 \% \\ & & & \\ & & & & \\ & & & \end{array}$




$\begin{array}{lcccc} & \text { Catholic } & \text { Other churches } & \text { Islam } & \text { Traditional } \\ \text { Not use } & 21 \% & 19 \% & 20 \% & 06 \% \\ \text { Use } & 79 \% & 81 \% & 80 \% & 94 \% \\ & & & \\ & & & & \\ & & & \end{array}$

Contraceptive

Occupation

Not wrk Prof. Cler Sales Ag-self Ag-emp Household Serv. Skill Unsk Oth

\begin{tabular}{lrrrrrrrrrrr} 
Not use & $18 \%$ & $20 \%$ & $31 \%$ & $20 \%$ & $19 \%$ & $14 \%$ & $08 \%$ & $27 \%$ & $25 \%$ & 0 & $50 \%$ \\
Use & $82 \%$ & $80 \%$ & $69 \%$ & $80 \%$ & $81 \%$ & $86 \%$ & $92 \%$ & $73 \%$ & $75 \%$ & $100 \%$ & $50 \%$ \\
& \multicolumn{8}{c}{$\mathbf{P = 0 . 0 0 5 9}$} \\
\hline
\end{tabular}

Contraceptive

\begin{tabular}{lll} 
& Urban & Rural \\
Not use & $22 \%$ & $18 \%$ \\
Use & $78 \%$ & $82 \%$ \\
& \multicolumn{2}{c}{$\mathbf{0 . 0 1 6 6}$} \\
\hline
\end{tabular}

Contraceptive

$\begin{array}{lccccc} & \text { Poorest } & \text { Poorer } & \text { Middle } & \text { Richer } & \text { Richest } \\ \text { Not use } & 16 \% & 15 \% & 14 \% & 21 \% & 23 \% \\ \text { Use } & 84 \% & 85 \% & 86 \% & 79 \% & 77 \% \\ & & & & \\ & & & & \\ & & & & \\ \end{array}$

Table4Sources Author's work 2016(Data from the 2013 NDHS)

Relationship between contraceptive use and intimate partner violence among married women in South-South Nigeria.

The table below shows relationship between contraceptive use and physical violence among married women in South-South Nigeria. This analysis is very important to be able to know if physical violence influences contraceptive use among married women in South-South Nigeria. The finding showed that there is no significant relationship between contraceptive use and physical violence among married women in South-South Nigeria $\mathrm{p}>0.05(\mathrm{p}=0.4389) .85 \%$ of married women in South-South Nigeria use contraceptive and reported experienced any physical violence while $15 \%$ did not use contraceptive and reported experienced any physical violence and $83 \%$ use contraceptive and reported experienced any physical violence while $17 \%$ did not use contraceptive and reported experienced any physical violence. 
This analysis is very important to be able to know if emotional violence influences contraceptive use among married women in South-South Nigeria. There is no significant relationship between contraceptive use and emotional violence $\mathrm{p}<0.05(\mathrm{p}=0.2957) .85 \%$ of married women in South-South Nigeria use contraceptive and reported not experienced any emotional violence while $15 \%$ did not use contraceptive and reported not experienced any emotional violence and $83 \%$ use contraceptive and reported experienced any emotional violence while $17 \%$ did not use contraceptive and reported experienced any emotional violence.

Follow relationship between contraceptive and sexual violence. This analysis is very important to be able to know if sexual violence influences contraceptive use among married women in South-South Nigeria. There is significant relationship between contraceptive use and sexual violence among married women in SouthSouth Nigeria $\mathrm{p}>0.05(\mathrm{p}=0.0143) .85 \%$ of married women in South-South Nigeria use contraceptive and reported not experienced any sexual violence while $15 \%$ not use contraceptive and reported not experienced any sexual violence and $78 \%$ use contraceptive and reported experienced any sexual violence while $22 \%$ not use contraceptive and reported experienced any sexual violence.

\section{Contraceptive Experienced any physical violence}

\begin{tabular}{lrr} 
& No & Yes \\
Not use & $15 \%$ & $17 \%$ \\
Use & $85 \%$ & $83 \%$ \\
& & \\
& & $\mathbf{P = 0 . 4 5 3 7}$ \\
\hline
\end{tabular}

\section{Contraceptive Experienced any emotional violence}

\begin{tabular}{lll} 
& No & Yes \\
Not use & $15 \%$ & $17 \%$ \\
Use & $85 \%$ & $83 \%$ \\
& & \\
\hline
\end{tabular}

Contraceptive experienced any sexual violence

\begin{tabular}{lcc} 
& No & Yes \\
Not use & $15 \%$ & $22 \%$ \\
Use & $85 \%$ & $78 \%$ \\
& $\quad \mathbf{P}=\mathbf{0 . 0 1 3 6}$ & \\
\hline
\end{tabular}

Table5 Sources Author's work 2016(Data from the 2013 NDHS)

\section{Discussion}

This study is to view intimate partner violence and contraceptive use among married women in SouthSouth Nigeria. Finding revealed that almost all married women in South-South Nigeria ever use 
contraceptive. Table5 showed that there is a significant relationship between married women whose experienced sexual violence and contraceptive use which implied that married women who have ever experienced sexual violence are more likely to adopt contraception when compare with other married women whose experienced physical violence and emotional violence.

Strengths of the study include age of married women, education, occupation, place of resident and wealth index. Table 4 revealed that almost all married women across the reproductive age 15-19(89\%), 2024(72\%), 25-29(76\%), 30-34(79\%), 35-39(84\%), 40-44(82\%) and 45-49(88\%) use contraceptive. Similarly, education and contraceptive is significantly related with the study which implied that almost all the married women in-respect of education level, no education (95\%), primary $(85 \%)$, secondary $(80 \%)$ and higher $(72 \%)$ use contraceptive. Likewise, the study revealed that there is significant relationship between occupation and contraceptive use which means that more than half of married women in occupation sectors from not working (82\%), professional $(80 \%)$, clerical $(69 \%)$, sales $(80 \%)$, to skilled $(75 \%)$ make use of contraceptive. Also, the table4 revealed that there is significant relationship between place of resident and contraceptive use. This showed that majority of married women in rural area (82\%) and $78 \%$ in urban center make use of contraceptive. This implied that more than half of married women lives in rural area. Furthermore, married women across the wealth status, poorest $(84 \%)$, poorer $(85 \%)$, middle $(86 \%)$, richer $(79 \%)$ and richest $(77 \%)$ which showed that almost all married women in all wealth index make use of contraceptive.

\section{Conclusion}

The present study revealed that married women in South-South Nigeria whose experienced sexual violence were more likely to use contraception as compare to counterpart married women whose experienced physical violence and emotional violence. Health care provider need to be sensitive to the issue of intimate partner violence while prescribing contraceptive advice.

\section{References}

1. Abramsky T, Watts C, Garcia-Moreno C, Devries K, Kiss L, et al. (2011) What factors are associated with recent intimate partner violence? Findings from the WHO multi-country study on women's health and domestic violence. BMC Publ Health 11: 109

2. Campbell JC (2002) Health consequences of intimate partner violence. The Lancet 359: 1331-1336.

3. Coker AL (2007) Does physical intimate partner violence affect sexual health? A systematic review. Trauma, Violence, \& Abuse 8: 149-177. doi: 10.1002/jts.21986.

4. Devries K, Mak J, García-Moreno C, Petzold M, Child J, et al. (2013) The global prevalence of intimate partner violence against women. Science 340: 1527-1528. Do10.1126/science.1240937.

5. Dutton MA, Kaltman S, Goodman LA, Weinfurt K, Vankos N (2005) Patterns of intimate partner violence: Correlates and outcomes. Violence and victims 20: 483-497.

6. Gee RE, Mitra N, Wan F, Chavkin DE, Long JA (2009) Power over parity: intimate partner violence and issues of fertility control. American journal of obstetrics and gynecology 201: 148. e141-148. e147

7. Hindin MJ, Kishor S, Ansara DL (2008) Intimate partner violence among couples in 10 DHS countries: predictors and health outcomes.

8. Salazar M, Valladares E, Hogberg U (2011) Questions about intimate partner violence should be part of contraceptive counselling: findings from a community-based longitudinal study in Nicaragua. Journal of Family Planning and Reproductive Health Care. doi: 10.1136/jfprhc-2011-000043.

9. Stephenson R, Jadhav A, Hindin M (2013) Physical domestic violence and subsequent contraceptive adoption among women in rural India. Journal of Interpersonal Violence 28: 1020-1039. doi: $10.1177 / 0886260512459379$.

10. Williams M, Larsen U, McCloskey (2008) Intimate partner violence and women's contraceptive use. Violence Against Women. ;14(12):1382-139

11. World Health Organization (2002); Intimate partner violence: Facts.

12. World Health Organization (2010); Preventing intimate partner and sexual violence against women: Taking 